\title{
O PROTRÉPTICO DE ARISTÓTELES, O HORTÊNSIO DE CÍCERO E A REFERÊNCIA DE SANTO AGOSTINHO ÀS ILHAS DOS BEM- AVENTURADOS NO LIVRO DE TRINITATE
}

\author{
Aristotle's Protrepticus, Cicero's Hortentius and Augustine's Reference to the Island \\ of The Blessed in the Book De Trinitate
}

Jorge Luís Gutiérrez ${ }^{1}$

\begin{abstract}
RESUMO: No capítulo 9 do livro XIV de sua obra De Trinitate, Santo Agostinho tem como propósito responder à pergunta se as virtudes desaparecerão na vida futura. Responde que é uma questão controversa saber se as virtudes, que alimentam uma vida reta nesta existência de adversidade, deixarão de existir após termos sidos conduzidos à vida eterna, pois lá não precisaremos delas. Agostinho entende a vida eterna como a vida junto a Deus, portanto, uma vida de felicidade plena. Para exemplificar essa situação, ele cita o texto do Hortênsio no qual se fala da Ilha dos Bem-Aventurados, que na mitologia grega corresponde a um lugar de felicidade e de recompensa, equivalente aos Campos Elíseos; no caso de Agostinho, trata-se do Paraíso ou Éden dos cristãos. Ele conclui que na outra vida não precisaremos das quatro virtudes cardinais. Elas serão somente uma fraca lembrança deixada em nossa alma quando passamos por este mundo. O que Agostinho não sabia é que a citação do Hortênsio era, de fato, uma citação do Protréptico de Aristóteles.
\end{abstract}

PALAVRAS-CHAVE: Agostinho; Aristóteles; Hortênsio; Protréptico; Virtudes.

\begin{abstract}
In Chapter 9 of Book XIV of The Trinity, Saint Augustine intends to respond to the question whether the virtues will disappear in the future life. He answers that it is a controversial question as to know if the virtues, which nourish a right life in this adverse existence, will no longer exist after we have been brought into eternal life; there we will no longer need them. For Augustine, eternal life means a life close to God, therefore, a fully blessed life. To give an example of this, he quotes the Hortensius, where the author mentions the Island of the Blessed, which, in Greek mythology, corresponds to a place of bliss and recompense. This is the equivalent of the Paradise or Eden of the Christians. He concludes saying that, in the afterlife, will no longer need of the cardinal virtues. They will remain only as a pale remembrance left in our soul when we still were in this world. What Augustine did not know is that the quotation of Hortensius was in fact a quotation of Aristotle's Protrepticus.
\end{abstract}

KEYWORDS: Augustine; Aristotle; Hortensius; Protrepticus; Virtues.

\footnotetext{
${ }^{1}$ Doutor em filosofia pela Universidade Estadual de Campinas (UNICAMP) e professor de filosofia na Pontifícia Universidade Católica de Campinas (PUC-Campinas). E-mail: jorgelrg@uol.com.br
} 
O filósofo espanhol Julián Marías afirmou em sua conhecida palestra sobre Santo Agostinho, que ele foi o primeiro grande filósofo e o primeiro criador filosófico dentro do cristianismo. $^{2}$ Com ele se inicia uma etapa nova da filosofia, isto é, finaliza a primeira etapa do pensamento filosófico centrado principalmente no pensamento grego, que tinha como principal problema a instabilidade do real e estava focado no problema da mudança e do movimento. Movimento (kinesis em grego), que faz com que as coisas sejam ou não sejam, existam e deixem de existir. Eles procuravam algo que fosse permanente, isto é, que fosse verdadeiramente. Mas o cristianismo introduz a ideia de que o mundo foi criado, e como sabemos, a ideia de criação é alheia ao pensamento grego.

Isso com certeza é um grau de radicalidade maior que o que se dá no pensamento grego, ou seja, o pensamento grego parte do pressuposto de que as coisas já estão aí. Uma pergunta crucial: por que há algo, e não somente o nada? É a formulação que Leibniz fará, e mais tarde Unamuno, e em terceiro lugar, Heidegger. Em geral, Unamuno é esquecido, mas ele diz isto e muito energicamente. ${ }^{3}$

Mas Santo Agostinho, ou Aurelius Augustinus, como ele próprio relata nas Confissões, não foi sempre cristão. Podemos afirmar que na primeira metade de sua vida foi pagão e a outra metade cristão. E sendo de pai pagão e mãe cristã ele sempre conheceu esses dois mundos, que as vezes conviveram pacificamente e outras em conflito. Assim, sendo pagão e vivendo no mundo romano, Santo Agostinho teve uma educação ao estilo dos jovens da sua época. E se é claro que essa educação teve uma profunda influência enquanto ele foi pagão, os biógrafos e estudiosos de Santo Agostinho sempre se perguntaram o que ele conservou, valorou ou utilizou da filosofia grega na sua vida de cristão.

Para os propósitos deste artigo nos interessa responder à pergunta sobre a presença da filosofia de Aristóteles na vida e educação de Santo Agostinho. Tema que tem sido pesquisado por importantes acadêmicos e produzido artigos de uma significativa relevância.

\section{O uso da Filosofia de Aristóteles por Santo Agostino}

Porém, antes de responder à pergunta sobre a influência de Aristóteles na obra de Santo Agostinho, uma questão mais geral se impõe: qual foi a relação de Agostinho

\footnotetext{
2 Julián Marías, Conferencia do curso Los estilos de la Filosofia, Madrid: ed. Renato José de Moraes, 1999/2000.

${ }^{3}$ Idem. p. 2.
} 
com a filosofia grega em geral? Esta pergunta foi respondida pelo pesquisador Hugo Emilio Costarelli Brandi, professor da Universidade Nacional de Cuyo, Argentina, em seu artigo intitulado: Agostinho de Hipona e a Filosofia. ${ }^{4}$ Nesse artigo Costarelli trata da relação do pensamento agostiniano com a filosofia antiga mostrando dois momentos dessa relação: primeiro, a incorporação da especulação platônico-neoplatônica como estrutura filosófica essencial do pensamento de Agostinho e, em segundo lugar, sua particular reconfiguração a partir da matriz intelectual cristã. Costarelli destaca como esta nova cosmovisão está sempre presente em Agostinho, e como na medida que a fé de Agostinho foi sendo mais intensa, é possível observar uma renovada elaboração da filosofia cristã. Por outro lado, a relação da filosofia de Aristóteles com Santo Agostinho foi o tema de um importante estudo de Kaufmann publicado no começo do século XX. ${ }^{5}$ Neste artigo Kausmann, após analisar as referências a Aristóteles na Epístola contra Fausto e a conhecida referência as "Categorias" no texto das confissões e outros lugares, opina que o juízo de Agostinho sobre as categorias de Aristóteles não é muito favorável ${ }^{6}$ e que embora Santo Agostinho foi principalmente, mas não exclusivamente, platônico, seu sistema também foi influenciado por Aristóteles. $^{7}$

Para Kaufmann, Agostinho teria usado a teoria aristotélica de matéria e forma, e de potência e ato de maneira indireta, especialmente através do neo-platonismo, principalmente de Plotino. Ele afirma que para melhor destacar a influência de Aristóteles sobre Santo Agostinho, não devemos esquecer que o neoplatonismo, do qual Agostinho recebeu uma importante influência, com exceção das teorias panteístas da emanação, não é uma reprodução exclusiva do platonismo, mas um sincretismo da filosofia platônica e aristotélica. Assim, a influência de Aristóteles em Agostinho é principalmente na lógica. Isto é mais claro ainda se se considera que Porfírio, o discípulo de Plotino, é o autor de uma introdução ao Organon. ${ }^{8}$

\footnotetext{
${ }^{4}$ COSTARELLI BRANDI, Hugo Emilio. Agustín de Hipona y la filosofía. Philosophia 72, 2012, p. 13-28.

${ }^{5}$ Kaufmann N. Éléments aristotéliciens dans la Cosmologie et la Psychologie de S. Augustin. In: Revue néo-scolastique. $11^{\circ}$ année, $\mathrm{N}^{\circ} 42,1904$. p. 140-156.

6 “Quoi qu'il en soit, le jugement porté par Augustin sur les Catégories d'Aristote n'est pas favorable". Idem.

7 "Saint Augustin était principalement, mais non exclusivement platonicien, et son système accuse des influences d'Aristote". Idem. p. 155.

8 "Pour mettre mieux en relief l'influence d'Aristote sur saint Augustin, il ne faut pas oublier que le néoplatonisme, auquel celui-ci rendait hommage à l'exception des théories panthéistes de l'émanation, n'est pas une reproduction exclusive du platonisme, mais un syncrétisme de philosophie platonicienne et aristotélicienne. L'influence d'Aristote se remarque principalement en logique; bien plus, Porphyre, le disciple de Plotin, est l'auteur d'une introduction à l' Organon”. Idem. p. 142.
} 
Essa influência, mencionada por Kaufmann, da Lógica de Aristóteles em Santo Agostinho, especialmente nos primeiros oito livros do tratado De Trinitae foi desenvolvida, mais de um século depois por Antonio Patativa de Sales, no artigo O "Aristotelismo agostiniano, através da lógica aplicada ao método teológico". 9 Patativa de Sales conclui que nas obras de Santo Agostinha há referências a Aristóteles, diretas ou indiretas, principalmente em De Trinitate, Confissões, De doctrina christiana, De civitate Dei. Assim, partindo da premissa de que até o século XII d.C., o tratado das "Categorias" e o tratado "Da interpretação" eram os únicos livros conhecidos na Idade Média latina, Sales indaga sobre o conhecimento que Agostinho tinha de Aristóteles, o modo como o utilizava e como teve acesso ao mesmo. Conclui que para

Para Santo Agostinho, a lógica é um instrumento essencial ao método teológico. Ela, e somente ela, é o que possibilita a sua progressão argumentativa, como pode ser verificado nos oito primeiros livros do tratado De Trinitate. ${ }^{10}$

Sales coloca como exemplo que nos capítulos 7 e 8 do livro $\mathrm{V}$ do tratado De Trinitate, Santo Agostinho usa as categorias aristotélicas de substância, acidente e relação, para fazer a distinção entre as pessoas da Trindade. Um outro artigo que analisa este tema é o de Emmanuel Falque, Dieu, la chair et l'autre: d'Irénée à Duns Scott. ${ }^{11}$ (Deus, a carne e o outro: de Irineu a Duns Scott). Neste artigo Emanule Falque analisa alguns conceitos teológicos - patrísticos e medievais -, à luz da fenomenologia. Especialmente os conceitos de "relação" e "substância" na doutrina da trindade e ontoteologia de Santo Agostinho.

O livro de Falque começa com um estudo muito bem elaborado dos livros V e VII do tratado De Trinitate de Agostinho. O título deste primeiro capítulo é Metafísica e teologia em tensão (Agostinho) ${ }^{12}$. O autor mostra como Agostinho, nestes dois livros de De Trinitate, retrabalhou as noções aristotélicas de "relacionamento" e "substância" aplicando-as a Deus. Sobre o mesmo tema podemos listar outro artigo que trata da relação da filosofia aristotélica com o a obra de Santo Agostinho. É “O peso do amor. Uma leitura de Confissões", de autoria de Hélène Machefert ${ }^{13}$. O artigo analisa a expressão "o amor é meu peso", que se encontra em Confissões XIII, 9, 10. Nesse parágrafo Santo Agostinho

\footnotetext{
9 PATATIVA, Antônio. Aristotelismo agostiniano, através da lógica aplicada ao método teológico. In: Revista INSTANTE, Campina Grande-PB-Brasil, julho-dezembro, 2018, V.1, N.1, p. 132-148.

${ }^{10}$ Idem.

${ }^{11}$ FALQUE, Emmanuel, Dieu, la chair et l'autre: D’Irénée à Duns Scott. Paris : Presses Universitaires de France, 2008, 494 p.

${ }^{12}$ Métaphysique et théologie en tension (Augustin). Idem, p. 49-85.

${ }^{13}$ MACHEFERT, Hélène, Le poids de l'amour : Une lecture de Confessions, XIII, 9, 10, p. 343-366.
} 
afirma que o que move o amor é o peso do amor. Uma expressão que nos remete ao livro da Física de Aristóteles, onde ele afirma que cada ser tende para o seu lugar natural. Para Agostinho, tendo como referência este texto aristotélico, o peso, em sua relação com a "medida" e o "modo-número" torna-se amor. Que não é outra coisa que a tendência da alma para retornar ao seu próprio lugar, o amor, onde ela finalmente encontrará seu descanso.

Há outro texto que também analisa a relação de Aristóteles com as Confissões de Santo Agostinho. É o artigo Agostinho, Aristóteles e as Confissões de autoria de Michael P. Foley ${ }^{14}$. Nesse artigo o autor analisa como, a partir da maneira que Agostinho insere nas "Confissões" o pensamento de Aristóteles, ele foi capaz de se beneficiar de vertentes nãoplatônicas da filosofia clássica. Sobre este tema também pode ser citado o artigo de_David Bradshaw, Agostinho o metafísico ${ }^{15}$, que analisa a relação entre o pensamento de Agostinho e a metafísica clássica de Platão, Aristóteles e Plotino.

Mas a pergunta principal continua: até que ponto Santo Agostinho conhecia Aristóteles? e, como o conhecia? Está pergunta foi respondida em seus aspectos fundamentais, e quase de uma maneira definitiva, no artigo "A recepção de Aristóteles por Santo Agostinho"16 de Juan Gramados Valdéz, professor da Universidade de Querétaro no México. Este artigo parte também da premissa que por volta do século IV a.C. os únicos tratados de Aristóteles que estavam disponíveis em latim eram os do Organon, e que o conhecimento de outras obras de Aristóteles se devia ao testemunho de outros autores. Assim, as traduções das "Categorias" e "Sobre a Interpretação", algumas Enéadas de Plotino e a tradução da "Isagoge" foram obra de Mario Victorino. Porém, considerando que Santo Agostinho em algumas de suas obras - como por exemplo "Sobre a doutrina cristã", "Sobre a dialética" e "A cidade de Deus", entre outras - faz menções explícitas de Aristóteles ou suas doutrinas, Juan Gramados Valdéz afirma que deve haver outros acessos à obra do filósofo macedônio. Assim, o artigo mostra as menções explícitas que San Agustín faz de Aristóteles em suas obras e os acessos indiretos por outras fontes à obra de Aristóteles; para deixar evidente o uso que Agostinho faz da filosofia do Estagirita.

\footnotetext{
${ }^{14}$ FOLEY, Michael P. _Agustín, Aristóteles y las Confesiones. Augustinus: Revista trimestral publicada por los Padres Agustinos Recoletos, ISSN 0004-802X, Vol. 54, Nº. 212-213, 2009, p. 185-197.

${ }^{15}$ BRADSHAW, David. Augustine the Metaphysician. Orthodox Readings of Augustine. St. Vladimir's Seminary Press, 2008, p. 227-251.

${ }^{16}$ GRANADOS VALDÉZ, J. (2020). La recepción de Aristóteles por San Agustín. Anales del Semanario de História de la Filosofía, 37(1), 13-21.
} 


\section{Agostinho e o Hortênsio}

É de esperar que tenha ficado claro, pelo exposto até aqui, que a temática da influência em Santo Agostinho da filosofia grega e especificamente Aristóteles, tem suscitado o interesse de muitos estudos da filosofia antiga. Pretendemos avançar um pouco nessa direção, trazendo novos elementos para a discussão.

É sabido que Santo Agostinho conhecia o Hortênsio de Cícero. Podemos concluir isto a partir das citações que Agostinho faz desse livro em vários lugares de sua obra e especialmente nas Confissões. Ele tinha nessa época dezenove anos. Nunca é demais relembrar este texto:

\footnotetext{
Entre essa gente estudava eu, em tão tenra idade, os livros da eloquência, na qual desejava sobressair com o fim condenável e vão de satisfazer à vaidade humana. Mas, seguindo o programa usado no ensino desses estudos, cheguei a um livro de Cícero, cuja linguagem, mais do que seu conteúdo, quase todos admiram. Esse livro contém uma exortação à filosofia, e se chama Hortênsio. Esse livro mudou meus sentimentos, e transferiu para ti, Senhor, minhas súplicas, e fez com que mudassem meus votos e desejos. Subitamente, tornou-se vil a meus olhos toda vã esperança, e com incrível ardor de meu coração suspirava pela sabedoria imortal, e comecei a me reerguer para voltar a ti. ${ }^{17}$
}

Podemos afirmar que o artigo fundamental sobre a influência do Hortênsio de Cícero em Santo Agostinho é A Influência do diálogo Hortênsio de Cícero em Santo Agostinho, de Carmen Dolby Múgica ${ }^{18}$. Neste artigo a autora começa firmando que "Um dos acontecimentos fundamentais na vida de Santo Agostinho foi o encontro providencial com o sábio e mestre da retórica Cícero." 19 Assim, de acordo com o artigo, a leitura do diálogo Hortênsio foi um dos elementos básicos da fé e da formação intelectual de Santo Agostinho e foi a leitura deste diálogo que levou Santo Agostinho a interessar-se e estudar Filosofia. Cícero forneceu para Santo Agostinho um vago conceito de Sabedoria que o fez ver que a felicidade não está no mundo material, mas no mundo espiritual. Porém santo Agostinho ficou decepcionado com o probabilismo de Cícero em assuntos tão importantes como Deus e a imortalidade da alma humana. Questões para as quais a

\footnotetext{
${ }^{17}$ SANTO AGOSTINHO. Confissões, Livro III, Cap. IV. Também sobre o mesmo tema pode ser citado o texto seguinte: "E quanto mais ardentemente amava aqueles jovens, cuja salutar decisão ouvia relatar, por se terem entregue completamente a ti para que os curasses, tanto mais acerbamente me odiava ao me comparar com eles. Com efeito, já tinham decorrido muitos anos - talvez uns doze - desde que, aos dezenove anos, lendo o Hortênsio de Cícero, sentira-me atraído para o estudo da sabedoria. Ia adiando a hora de abandonar a felicidade meramente terrena, quando não somente a sua descoberta, mas a sua própria busca, deveria ser preferida aos maiores tesouros do mundo e aos maiores prazeres corporais, que a um aceno, afluíam a meu redor." Confissões, Livro VIII, Cap. VII.

${ }^{18}$ DOLBY MÚGICA, Carmen. La Influencia del diálogo Hortensio de Cicerón en San Agustín. Anuario Filosófico, 2001 (34), 555-564.

19 "Uno de los sucesos fundamentales en la vida de san Agustín fue su providencial encuentro con el sabio y maestro de retórica, Cicerón. Idem, p. 555.
} 
doutrina cristã tinha uma resposta muito mais valiosa. De alguma forma, o diálogo de Cícero o Hortênsio trouxe Santo Agostinho ao pensamento cristão. Mas de que tratava o Hortênsio e qual era seu conteúdo?

O Hortênsio foi um exame crítico de todas as escolas ou seitas filosóficas, apontando os erros e inconvenientes de cada uma, para chegar à conclusão de um ecletismo filosófico, ideal e equilibrado, caráter fundamental da filosofia de Cícero. É quase certo que o Santo não compreendeu nessa época, nem muito depois, o aspecto e tendência do famoso Diálogo, marcadamente cético, apesar de que ao final dele podem ser lidas frases neste sentido que não deixam lugar às dúvidas. Mas o jovem estudante de Cartago não via nele senão a beleza: a exortação calorosa e esplêndida que fazia o leitor buscar a verdadeira sabedoria. ${ }^{20}$

Mas também é sabido pelos estudiosos e pesquisadores que o Hortênsio reflete em muitas de suas partes o "Protréptico", obra da juventude de Aristóteles. O Protréptico de Aristóteles é uma obra de exortação à filosofia, entendida como a pesquisa racional e metódica da natureza das coisas e, principalmente, dos princípios e causas que a sustentam, bem como das condições e possibilidade de tal pesquisa. ${ }^{21}$ Assim, o Protréptico influenciou o Hortênsio e esta obra influenciou Santo Agostinho, pelo que o Protréptico, isto é, Aristóteles, influenciou Santo Agostinho. Se $A=B$ e B=C, então $\mathrm{A}=\mathrm{C}$. Sobre isto, Carlos Megino Rodríguez em seu estudo introdutório ao Protréptico ${ }^{22}$ afirma:

A obra como tal teve grande difusão e influência nos círculos cultos, como testemunha, por exemplo, a anedota que relata Zenão de Citius sobre a leitura do Protréptico por seu mestre Crátes, o cínico, a um sapateiro, uma influência que perdurou também em séculos posteriores,

${ }^{20}$ Obras de San Agustín. Texto bilingüe II. Las Confesiones. Edición crítica y anotada por el padre Ángel Custodio Vega. Séptima edición ( $8^{\mathrm{a}}$ del autor). Biblioteca de Autores Cristianos. Madrid. MCMLXXIX. Notas do Livro III, nota de rodapé $n^{\circ} 21$. O texto original em español é o seguinte: "El Hortensio-como se deduce de estas palabras y las referencias que de él nos han dejado otros autores - era un examen crítico de todas las escuelas o sectas filosóficas, señalando los errores e inconvenientes de cada urna, para llegar a la conclusión de un eclecticismo filosófico, ideal y templado, carácter fundamental de la filosofía de Cicerón. Es casi seguro que el Santo no comprendió en esta época, ni en mucho después, el aspecto y tendencia del célebre Diálogo, marcadamente escéptico, no obstante que al final del mismo se leían frases en este sentido que no dejaban lugar a dudas. Pero el joven estudiante de Cartago no vio en él más que su aspecto bueno: la exhortación cálida y esplendente que hacía al lector a buscar la verdadera sabiduría"

${ }^{21}$ ARISTÓTELES. Protréptico. Una exhortación a la Filosofia. Madrid: Abada Editores, 2006. p. 5. A citação completa em espanhol é a seguinte: "El Protréptico de Aristóteles es una obra de exhortación a la filosofía, entendida ésta como la investigación racional y metódica de la naturaleza de las cosas y, en especial, de los principios y causas que la fundamentan, así como de las condiciones de posibilidad de dicha investigación. Está dirigido al rey Temisonte de Chipre, con la intención, posiblemente, de extender la influencia del ideal filosófico y político de la Academia en la clase dirigente chipriota, en competencia con la escuela de Isócrates, quien ya había dirigido varios discursos políticos a dos reyes de la isla en los años anteriores. No obstante, su dedicatoria personal, se trata de una de las obras que el Estagirita publicó en vida y, por tanto, pensadas para su difusión fuera de los muros de la Academia, lo que nos indica que el destinatario final fue el público ateniense y, en concreto, aquellos jóvenes susceptibles, por su afición y talento, de dedicarse a la filosofía"

${ }^{22}$ Idem. p. 6. 
se advertirmos a marca do Protréptico no Hortênsio de Cícero e através deste, em Santo

Agostinho. ${ }^{23}$

Sobre as pegadas do Protréptico no Hortênsio de Cícero e, a través dele, em Santo Agostinho, Carlos Megino Rodríguez cita como fonte os artigos de Bignone (1936) e Moraux (1951). ${ }^{24}$ Dois textos são bons exemplos de como os textos de Aristóteles passaram para Agostinho através do Hortênsio:

a) O texto da "Ilhas dos bem-aventurados": Protréptico 43", Citado por Santo Agostinho em $A$ trindade 14.9.12. Neste texto Agostinho começa dizendo: “..., num diálogo do Hortênsio, o grande mestre de retórica, Túlio Cicero diz:..". Possivelmente Agostinho não sabe que citando Cicero está citando Aristóteles.

b) O segundo texto é o de Protréptico, apêndice, 8 (fr. 115 Grilli), citado através do Hortênsio por Agostinho em $A$ trindade 14.19.26. Neste texto Agostinho discute alguns aspectos da filosofia. E novamente (sem saber?) Agostinho está citando Aristóteles.

Porém, como o objetivo do presente artigo é estudar a menção das Ilhas dos bemaventurados no Texto de Agostinho, devemos fixar nossa atenção unicamente no primeiro texto, no qual Santo Agostinho menciona as "beatorum insulis":

Se, ao emigrarmos desta vida, for-nos permitido viver uma vida imortal nas ilhas dos bem-aventurados, como contam as fábulas, para que serviria a Retórica, não existindo pleitos, e mesmo, para que serviriam as virtudes? Não necessitaríamos da fortaleza, não havendo absolutamente trabalho ou perigo; nem da justiça, não havendo nada a ambicionar do alheio; nem da temperança, moderadora das paixões que não existiriam; e não teríamos tampouco necessidade da prudência, não existindo escolha entre o bem e o mal. Seríamos, portanto, felizes apenas com o conhecimento da natureza, pela ciência, o único que torna louvável a vida dos próprios deuses. Por onde se pode compreender que, se tudo mais depende da necessidade, isso só depende da vontade" ${ }^{25}$

\footnotetext{
23 "La obra como tal sí tuvo una gran difusión e influencia en círculos ilustrados, como testimonia, p. e., la anécdota que relata Zenón de Citio sobre la lectura del Protréptico que hizo su maestro, Crates el cínico, a un zapatero, influencia que perduró también en siglos posteriores, si constatamos la huella del Protréptico en el Hortensio de Cicerón y, a través de éste, en San Agustín”. Idem., p. 6.

${ }^{24}$ BIGNONE, E., L'Aristotele perduto e la formazione filosofica di Epicuro, I-II. Florencia, 1936, p. 43s. MORAUX, P., Les listes anciennes des ouvrages d'Aristote, Louvain, 195I, 33 n. 36. BIGNONE, E., Nuove testimonianze e frammenti del Protrettico di Aristotele, RFIC (1936), pp. 225-237.

25 "Si nobis, inquit, cum ex hac vita emigraverimus, in beatorum insulis immortale aevum, ut fabulae ferunt, degere liceret, quid opus esset eloquentia, cum iudicia nulla fierent; aut ipsis etiam virtutibus? Nec enim fortitudine egeremus, nullo proposito aut labore aut periculo; nec iustitia, cum esset nihil quod appeteretur alieni; nec temperantia, quae regeret eas quae nullae essent libídines; nec prudentia quidem egeremus, nullo delectu proposito bonorum et malorum. Uma igitur essemus beati cognitione naturae et scientia, qua sola etiam deorum est vita laudanda. Ex quo intelligi potest, cetera necessitatis esse, unum hoc voluntatis". Santo Agostinho. A Trindade, livro 9, Capitulo XIV, 12. Para o texto em latim: Obras de San Agustín en edición bilingüe, tomo V, Tratado sobre La Santísima Trinidad. Primera versión española, introducción y notas del padre Fr. Luis Arias, O. S. A. Madrid. MCMLVI. Para o texto em português: Santo Agostinho. A Trindade. São Paulo: Paulos, 1994.
} 


\section{As Ilhas dos Bem-aventurados}

Como já mencionamos anteriormente, Aristóteles se refere, no Protréptico, às Ilhas dos Bem-aventurados ( $\mu \alpha \kappa \alpha ́ \rho \omega v ~ v \eta ́ \sigma o v \varsigma))^{26}$ :

Se poderia ver que o que dizemos é antes de tudo a verdade se alguém nos conduzisse com o pensamento

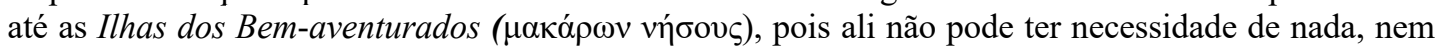
proveito de nenhuma outra coisa; só fica pensar e contemplar, o que inclusive agora chamamos precisamente uma vida livre ( $\varepsilon \lambda \varepsilon v ́ \theta \varepsilon \rho o v$ $\varphi \mu \mu \varepsilon v$ Bíov cíval) ${ }^{27}$

Nesta obra, considerada ainda do período da Academia, Aristóteles relaciona a vida livre com o pensar e o contemplar. Mas isso só é possível num lugar que os antigos chamaram de Ilhas dos Bem-aventurados. No livro IV da Política, agora no Liceu, Aristóteles voltará a falar dessas ilhas:

Há, sobretudo, maior necessidade de justiça e de prudência quando se está à cume da prosperidade, e se goza de tudo o que excita a inveja dos demais homens. Sucede o que com os bem-aventurados

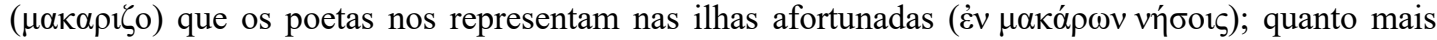
completa é sua beatitude tanto mais devem chamar em seu auxílio à filosofia, a moderação e a justiça

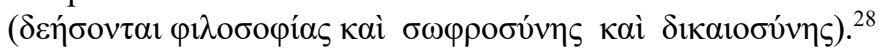

Porém, como já mencionamos, Aristóteles não foi o primeiro a falar da "Ilhas dos Bem-aventurados”. Hoje podemos constatar que essas ilhas são mencionadas em vários textos anteriores a Aristóteles e, como pretendemos demostrar neste artigo, também em textos posteriores. Por isso queremos, antes de analisar o texto de Santo Agostinho, apresentar alguns dos textos que falam das ilhas dos "bem-aventurados" na literatura que precedeu Aristóteles. ${ }^{29}$

${ }^{26}$ Para o texto em grego do Protréptico, com tradução para o inglês: ARISTOTLE. Protrepticus or Exhortation to Philosophy (citations, fragments, paraphrases, and other evidence). Hutchinson and Monte Ransome Johnson, 2017. http://www.protrepticus.info

27 "Se podría ver que lo que décimos es ante todo la verdad si alguien nos condujera con el pensamiento hasta las Islas de los Bienaventurados, pues allí no puede haber necesidad de nada, ni provecho de ninguna otra cosa; solo queda pensar y contemplar, lo que incluso ahora llamamos precisamente una vida libre. Y si esto es verdad, ¿cómo no se avergonzaría con justicia cualquiera de nosotros que, teniendo la facultad de vivir en las Islas de los Bienaventurados, fuera incapaz de hacerlo por culpa propia? Por tanto, no es despreciable la recompensa que reciben los hombres de la ciencia, ni es tampoco pequeño el bien que proviene de ella, pues, según afirman los sabios entre los poetas, así como recibimos en el Hades los dones de la justicia, así también, como es de suponer, recibiremos los de la sabiduría en las Islas de los Bienaventurados". ARISTÓTELES. Protréptico: Una exhortación a la Filosofía. Madrid, Abada Editores, 2006. Frag. 43. A tradução é nossa.

${ }^{28}$ Não esqueçamos que para Aristóteles a felicidade pode ser considerada como uma espécie de

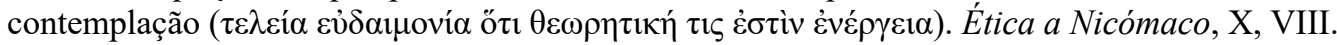

${ }^{29}$ Para uma história do mito das Ilhas dos Bem-aventurados nos períodos arcaicos e clássicos da literatura na Grécia, recomendamos os seguintes artigos e ensaios: MARTÍN Hernández, Marcos. Las Islas de los Bienaventurados: Historia de un mito en la literatura griega arcaica y clásica. Cuadernos De Filología Clásica. Estudios Griegos e Indoeuropeos, 9, 243. SANTAMARÍA ÁLVAREZ, Marco Antonio. El edén griego: las islas de los bienaventurados, de Hesiodo a Platón. Respublica Litterarum, Suplemento Monográfico Utopía, 2006-1. SANTOS YANGUAS, N. (1988). El mito de las islas afortunadas en la 
Possivelmente a referência mais antiga que temos à "Ilhas dos Bem-aventurados" é do poeta grego Hesíodo, que viveu por volta do século VII a. C. Em "Os trabalhos e os dias" ${ }^{30}$, obra que hoje é considerada uma das mais importantes da antiguidade. Hesíodo fala das Ilhas dos Bem-aventurados quando descreve a quarta geração de Zeus Crônidas, que foram chamados de semideuses. Que eram mais justos e melhores que a geração anterior, a dos homens falantes da idade do bronze. Nessa época a terra estava cheia de guerras terríveis. Por isso os semideuses foram morrendo vítimas dos conflitos. Alguns morreram na terra de Cadmeida. Outros morreram combatendo pelos rebanhos de Édipo em Tebas ("“a das sete portas'), outros morreram na guerra de Troia ("por causa de Helena a de formosos cabelos"). A todos eles o Pai Zeus lhes deu uma morada desconhecida dos homens, nos confins da terra. Esse lugar era a "Ilhas dos Bem-aventurados", que estava localizada além do profundo oceano. Lugar onde a terra dá três vezes ao ano seus frutos.

O poeta Píndaro (século V a.C.) também descreveu com alguns detalhes a Ilhas dos Bem-aventurados, em suas "Odes Olímpicas”. Para ele é um lugar ideal, o reino de Cronos, para premiar aqueles que a vitória coroou seus esforços:

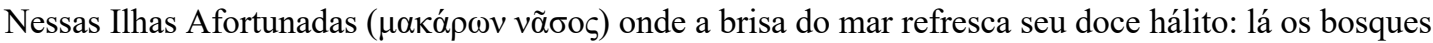
adornam com perfumadas sombras o curso dos riachos e prados são pontilhados com milhares de flores de ouro, com as quais tecem suas coroas os habitantes para decorar seu peito e a testa". ${ }^{31}$

A descrição das ilhas dos bem-aventurados como um lugar de condições ideais — solo fértil, frutos, água e condições excelentes para a vida - levou muitos escritores a associar essas ilhas com o infra mundo (ou submundo), pois seria difícil encontrar "nestemundo" um lugar com as excelentes características descritas pelos poetas. Se esse lugar existia, não podia estar neste mundo. Assim, muitos poetas da antiguidade, pensaram que essas ilhas eram os campos Elíseos ${ }^{32}$, que é, possivelmente, a representação antiga do que depois será o paraíso e o Éden dos cristãos. Na mitologia grega, as Ilhas dos Bem-

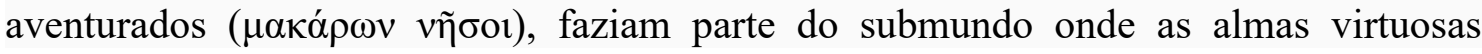
ganhavam um perfeito descanso após sua morte. Elas serão citadas, além de Aristóteles, por Platão e Honorato. E para demostrar que após Santo Agostinho esta palavra ainda continuou sendo usada, podemos citar as Etimologias de Isidoro de Sevilla. Ele esclarece

Antigüedad. In Memorias de Historia Antigua. Oviedo, 9, p. 166 - 175. SCHULTEN, A. (1945 - 1946). Las Islas de los Bienaventurados. In Ampurias. Barcelona, 7-8, p. 5- 22.

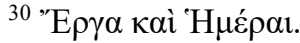

${ }^{31}$ PINDARO, Olympian 2,5 e PLUTARCO. Sert. 8, 2.

${ }^{32} \mathrm{O}$ texto mais antigo no qual se citam os Campos Elísios é $A$ Odisseia de Homero $(4,561-9)$ : “Os imortais

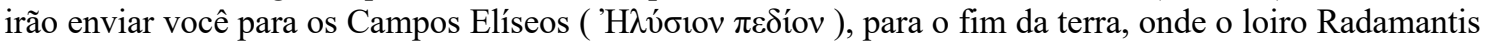
é encontrado - lá os homens vivem felizes, nunca há neve, nem inverno longo, nem chuva, mas o oceano sempre envia as brisas do Zéfiro , com um sopro forte, para dar mais frescor aos homens...". 
que o nome "Fortunatarum insulae" é dado a essas ilhas porque além de produzir toda classe de bens, elas são consideradas felizes e ditosas pela abundância de seus frutos. Na sua descrição das Fortunatarum insulae Isidoro disse que nelas as mais preciosas árvores produzem frutos de maneira espontânea; os cumes das colinas se cobrem de videiras sem necessidade de plantá-las; em lugar de ervas, nascem por todos os lados frutos (messis) e legumes. ${ }^{33}$ Mas, será que estas ilhas estão localizadas em algum lugar geográfico? Isidoro responde afirmativamente. Elas estão situadas no oceano, em frente e à esquerda de Mauritânia $^{34}$, próximas ao ocidente da mesma, e separadas ambas pelo mar. Possivelmente sejam as atuais ilhas Canarias ${ }^{35}$.

\section{Santo Agostinho e a Ilhas dos Bem-aventurados}

Santo Agostinho começou a escrever De Trinitate por volta de 399 d.C. e a teria finalizado essa obra 20 anos depois, em 419 ou 420. Santo Agostinho além de conhecer a filosofia grega também conhecia a mitologia Grega. Ao ponto de mencionar o antigo mito grego da Ilhas dos Bem-aventurados num livro que trata de um tema eminente cristão: A Trindade. A questão que Santo Agostinho está tratando é o papel das virtudes morais na vida futura (céu, Éden, Paraiso) e concretamente quer responder à pergunta se desaparecerão as virtudes nessa vida futura.

Santo Agostinho começa afirmando que é uma questão polêmica se as virtudes pelas quais se vive honestamente nesta vida mortal irão desaparecer uma vez que sejamos levados às mansões eternas, visto que elas têm um início na alma, porém a alma já existia antes de adquirir as virtudes. Seguidamente coloca com maior clareza a controvérsia: parece a alguns que elas vão cessar, e sua opinião pode parecer verdadeira se for sobre as três virtudes cardeais: prudência, fortaleza e temperança ${ }^{36}$; mas a justiça é imortal e o

\footnotetext{
33 "Fortunatarum insulae vocabulo suo significant omnia ferre bona, quasi felices et beatae fructuum ubertate. Sua enim aptae natura pretiosarum poma silvarum parturiunt; fortuitis vitibus iuga collium vestiuntur; ad herbarum vicem messis et holus vulgo est. Unde gentilium error et saecularium carmina poetarum propter soli fecunditatem easdem esse Paradisum putaverunt.." "De manera espontánea producen frutos los más preciados árboles; las cimas de las colinas se cubren de vides sin necesidad de plantarlas; en lugar de hierbas, nacen por doquier mieses y legumbres. De ahí el error de los gentiles y de los poetas paganos, según los cuales, por la fecundidad del suelo, aquellas islas eran el paraíso." San Isidoro de Sevilla. Etimologías. Biblioteca Autores Cristianos, Madrid, 2004, Capitulo XIV, 6. Verbete: "De insulis". Na edição citada corresponde às áginas 1024 (latim) e 1025 (espanhol).

34 "Sitae sunt autem in Oceano contra laevam Mauretaniae, occiduo proximae, et inter se interiecto mari discretae". Idem.

35 Idem.

${ }^{36}$ Prudentia, fortitudine, temperantia. DE TRINITATE, XIV, 9, 12.
} 
mais provável é que ela seja aperfeiçoada em nós antes de deixar de existir ${ }^{37}$. É neste ponto que Santo Agostinho traz o texto do Hortênsio para a discussão. E concretamente cita o texto do "grande mestre de Retórica, Túlio Cicero" no qual ele disputa sobre as quatro virtudes ${ }^{38}$. Então ele cria uma “ficção literária". É algo hipotético, por isso começa com um "si". Ele usa a palavra "fábulas" (latim: fabulae) para referir-se ao que vai citar. O vocabulário é técnico, próprio do mestre de retorica que era Santo Agostinho.

$\mathrm{Se}$, ao emigrarmos desta vida, for-nos permitido viver uma vida imortal nas ilhas dos bem-aventurados, como contam as fábulas, para que serviria a Retórica, não existindo pleitos, e mesmo, para que serviriam as virtudes? $?^{39}$

Pelo que foi dito anteriormente, embora brevemente, sobre a ilhas dos bemaventurados, sabemos que é um lugar ideal, no qual se vive feliz e sem necessidades. Por isso podemos entender a razão pela qual Santo Agostinho faz a pergunta. Que no fundo pode ser entendida como se vamos precisar as quatro virtudes cardinais na Ilhas dos Bemaventurados, que no caso de Santo Agostinho pode ser entendido como o céu, ou o Éden, dos cristãos. ${ }^{40}$

Lembremos que anteriormente em XII, 14, 22 agostinho tinha afirmado sem a ciência, não se podem adquirir as virtudes, e que sem estas virtudes não se pode levar uma vida reta e governar esta mísera existência, para assim alcançar a verdadeira vida feliz que é a eterna. Então as virtudes são de muita utilidade para poder passar por esta "mísera existência". Porém, quando deixarmos esta vida e a existência deixe de ser miserável, será que ainda precisaremos das virtudes? Santo agostinho, citando ainda o Hortênsio, descreve bem as rações pelas quais não precisaremos das virtudes

Não necessitaríamos da fortaleza, não havendo absolutamente trabalho ou perigo; nem da justiça, não havendo nada a ambicionar do alheio; nem da temperança, moderadora das paixões que não existiriam; e não teríamos tampouco necessidade da prudência, não existindo escolha entre o bem e o mal. ${ }^{41}$

\footnotetext{
37 "Iustitia vero immortalis est, et magis tune perficietur in nobis, quam esse cessabit". DE TRINITATE, XIV, 9, 12.

38 "De ómnibus tamen quatuor magnus auctor eloquentiae Tullius in Hortensia dialogo disputans". $D E$ TRINITATE, XIV, 9, 12.

39 "Si nobis, inquit, cum ex hac vita emigraverimus, in beatorum insulis immortale aevum, ut fabulae ferunt, degere liceret, quid opus esset eloquentia, cum iudicia nulla fierent; aut ipsis etiam virtutibus?". $D E$ TRINITATE, XIV, 9, 12.

40 Sobre a relação das Ilhas dos Bem-aventurados com o Éden dos cristão, recomendamos a leitura do artigo: SANTAMARÍA ÁLVAREZ, Marco Antonio. El Edén griego: las islas de los bienaventurados, de Hesíodo a Platón. Respublica Litterarum, Suplemento Monográfico Utopía, 2006.

41 "Nec enim fortitudine egeremus, nullo proposito aut labore aut periculo; nec iustitia, cum esset nihil quod appeteretur alieni; nec temperantia, quae regeret eas quae nullae essent libídines; nec prudentia quidem egeremus, nullo delectu proposito bonorum et malorum. Upa igitur essemus beati cognitione naturae et scientia, qua sola etiam deorum est vita laudanda. Ex quo intelligi potest, cetera necessitatis esse, unum hoc voluntatis". DE TRINITATE, XIV, 9, 12.
} 
Assim não tendo trabalhos, nem perigos, nem ambição das coisas dos outros, nem paixões, e sem ter que escolher entre o bem e o mal, as pessoas serão felizes nesse lugar, apenas com o conhecimento e a ciência da natureza, o único bem louvável na vida dos deuses. Tudo dependerá só da vontade e nada da necessidade ${ }^{42}$. Santo Agostinho, parece concordar plenamente com a conclusão de Cícero, que realmente são de Aristóteles, isto é que as quatro virtudes (prudência, fortaleza, temperança e justiça) são necessárias apenas durante esta vida, cheia de tribulações e fadigas. E nenhuma delas será necessária quando deixarmos esta vida presente, quando vivamos lá, nesse lugar onde seremos felizes, isto é, nas ilhas dos bem-aventurados. Lá as boas almas serão abençoadas pelo conhecimento e pela ciência, isto é, pela contemplação daquela natureza extremamente perfeita e adorável; natureza criadora de todas as outras naturezas. Porém, se a justiça está submedida a um governo desta natureza, como a justiça é imortal ela não deixará de existir naquela vida feliz, e será cada vez maior e mais perfeita. Santo agostinho escreve que a sobrevivência das outras três virtudes é até possível na felicidade (a beatitude) das "Ilhas dos Bem-aventurados". Onde haverá a prudência, sem perigo de erro; a força, sem males irritantes; e a temperança, sem desejos opostos. Mas nesse lugar sem necessidades, qual seria o rol dessas virtudes? Santo Agostinho responde:

Nesse caso, seria próprio da prudência não preferir ou igualar bem algum a Deus; da fortaleza, aderir a ele com toda firmeza; da temperança, não se deleitar com gozo algum culpável. Quanto às funções da justiça, como aqui neste mundo, ela destina-se a socorrer os fracos; a prudência em precaver-se das ciladas; a fortaleza em suportar os incômodos da vida; e a temperança em coibir os prazeres depravados; nenhuma delas, nesse sentido, existirá na outra vida, pois lá não haverá mal algum. Por isso, as obras dessas virtudes, necessárias a esta vida mortal, assim como a fé, à qual se referem, serão consideradas obras do passado. ${ }^{43}$

Para Santo Agostinho, quando essas realidades estão presentes na memória e as contemplamos e as amamos, elas formam uma certa trindade; porém, na outra vida formarão outra trindade, quando, veremos que não existem mais, mas existiram só por alguns vestígios que deixaram na memória quando se efetuou a mudança de vida.

Haverá, pois, uma nova trindade quando qualquer pequeno vestígio que seja retido na memória, for reconhecido na verdade, e quando as duas realidades ficarem unidas pela vontade, como terceiro elemento. $^{44}$

\footnotetext{
42 "Ex quo intelligi potest, cetera necessitatis esse, unum hoc voluntatis". DE TRINITATE, XIV, 9, 12.

43 "Ut prudentiae sit nullum bonum Deo praeponere vel aequare; fortitudinis, ei firmissime cohaerere; temperan tiae, nullo defeetu noxio delectan. Nunc autem quod agit iustitia in subveniendo miseris, quod prudentia in praeca/vendis insidiis, quod fortitudo in perferendis molestiis, quod temperantia in coercendis delectationibus pravis. non ibi erit, ubi nihil omnino mali erit. Ac per hoc ista virtutum opera, quae huic mortali vitae sunt necessaria, sicut fides ad quam referenda sunt, in praeteritis habebuntur. DE TRINITATE, XIV, 9, 12.

44 "Quia et tune trinitas erit, cum illud qualecumque vestigium et memoriter retinebitur, et agnoscetur veraciter, et hoc utrumque tertia volúntate iungetur". DE TRINITATE, XIV, 9, 12.
} 
Deste modo Santo Agostinho termina o capítulo 9 do livro XIV de sua obra $D e$ Trinitate. Ele tinha acrescentado um novo elemento as "Ilhas dos bem-aventurados": é o lugar onde pode ser contemplado um tipo especial de natureza. Para Santo Agostinho “essa natureza é a que criou todas as outras e é assim a autora de todas as naturezas". Com certeza Santo Agostinho estava falando de Deus.

Ele citou Cícero, sem saber que estava citando Aristóteles. Mas, possivelmente, ele teria citado igualmente este texto se tivesse sabido que era de Aristóteles.

\section{Conclusão}

O ponto de partida do artigo foi a constatação de que Santo Agostinho cita no livro A Trindade as "beatorum insulis". Estas ilhas formavam parte da mitologia grega, mas também tinham sido citadas por Aristóteles no Protréptico, e por outros filósofos como Platão. Aristóteles fala claramente da "Ilhas dos Bem-aventurados" no Protréptico e na Política. E de uma maneira indireta na Ética a Nicômaco. No Protréptico (Fr. 43) ele afirma que na Ilhas dos Bem-aventurados ( $\mu \alpha \kappa \alpha ́ \rho \omega v ~ v \eta ́ \sigma o v \varsigma)$ não precisaríamos de nada e não teríamos vontade de nenhuma outra coisa: só subsistiriam nelas o pensamento e a

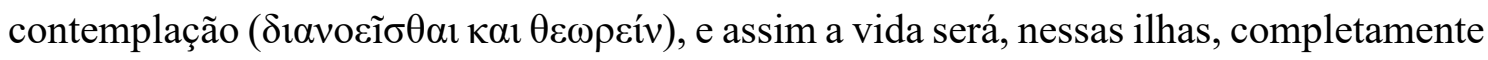

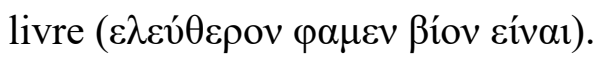

Este texto de Aristóteles será citado séculos mais tarde pelo poeta Cícero em sua obra Hortênsio. Aristóteles e Cícero citam as Ilhas dos Bem-aventurados para abordar da relação entre a felicidade e a vida teorética. Para eles só numa vida na qual nada falte é possível a vida teorética perfeita, isto é, a vida contemplativa, e consequentemente a vida dedicada a filosofia.

Por isso, analogamente, quando Santo Agostino, no capítulo 9 do livro XIV de seu livro De Trinitate, se propõe responder à questão se as virtudes desaparecerão na vida futura cita as "beatorum insulis" para evocar um lugar onde existe uma vida de felicidade plena, na qual não há necessidade de nada. Pois, as Ilha dos Bem-Aventurados representam na mitologia grega um lugar de felicidade e de recompensa. Equivalente aos Campos Elíseos, e no caso de Agostinho ao Paraiso ou Éden dos cristãos. Ele cita a mitologia grega para deixar claro uma doutrina crista.

E conclui que na outra vida não precisarão das quatro virtudes cardinais. Elas serão só essa fraca lembrança que deixaram quando eram necessárias para poder passar por este mundo de miséria, ou seja, por esta vida presente. 


\section{Referências}

\section{Fontes primarias}

SAN AGUSTÍN, Obras de. Texto bilingüe II. Las Confesiones. Edición crítica y anotada por el padre Ángel Custodio Vega. Séptima edición ( $8^{\mathrm{a}}$ del autor). Biblioteca de Autores Cristianos. Madrid. MCMLXXIX.

SAN AGUSTÍN, Obras de en edición bilingüe, tomo V, Tratado sobre La Santísima Trinidad. Primera versión española, introducción y notas del padre Fr. Luis Arias, O. S. A. Madrid. MCMLVI.

SANTO AGOSTINHO. A Trindade. São Paulo, Paulos. 1994.

ARISTÓTELES. Protréptico. Una exhortación a la Filosofía. Madrid, Abada Editores, 2006.

ARISTOTLE. Protrepticus or Exhortation to Philosophy (citations, fragments, paraphrases, and other evidence). Edited and translated by D. S. Hutchinson and Monte Ransome Johnson. Hutchinson and Monte Ransome Johnson, 2017.

\section{Artigos e livros}

BRADSHAW, David. Augustine the Metaphysician, Orthodox Readings of Augustine, ed. Aristotle Papanikolaou and George Demacopoulos (St. Vladimir's Seminary Press, 2008), 227-251.

COSTARELLI BRANDI, Hugo Emilio. Agustín de Hipona y la filosofía. Philosophia 72, 2012, p. 13-28.

DOLBY MÚGICA, Carmen. La Influencia del diálogo Hortensio de Cicerón en San Agustín. Anuario Filosófico, 2001 (34), 555-564.

FALQUE, Emmanuel, Dieu, la chair et l'autre: d'Irénée à Duns Scott, Paris, Presses Universitaires de France, 2008.

FOLEY, Michael P. Agustín, Aristóteles y las Confesiones. Augustinus: revista trimestral publicada por los Padres Agustinos Recoletos, ISSN 0004-802X, Vol. 54, No. 212-213, 2009, págs. 185-197.

GRANADOS VALDÉZ, J. (2020). La recepción de Aristóteles por San Agustín. Anales del Semanario de Historia de la Filosofía, 37(1), 13-21.

JULIÁN MARÍAS, Conferencia do curso Los estilos de la Filosofia, Madrid, 1999 2000. Edição: Renato José de Moraes. Tradução: Ho Yeh Chia (http://www.hottopos.com). 
KAUFMANN N. Éléments aristotéliciens dans la Cosmologie et la Psychologie de $S$. Augustin. In: Revue néo-scolastique. $11^{\circ}$ année, N42, 1904. pp. 140-156.

MACHEFERT, Hélène, Le poids de l'amour. Une lecture de Confessions, XIII, 9, 10, p. 343-366.

MARTÍN Hernández, Marcos. Las Islas de los Bienaventurados: Historia de un mito en la literatura griega arcaica y clásica. Cuadernos De Filología Clásica. Estudios Griegos e Indoeuropeos, 9, 243.

PATATIVA, Antônio. Aristotelismo agostiniano, através da lógica aplicada ao método teológico. Revista INSTANTE, Campina Grande-PB-Brasil, julho-dezembro, 2018, V.1, N.1, p. 132-148.

PÍNDARO, Odas de. Traducción, prólogo y notas Ignacio Montés de Oca. Disponível em: http://cdigital.dgb.uanl.mx/la/1080018724/1080018724.html.

PLUTARQUE, Oeuvres Complètes. Disponível em:

http://remacle.org/bloodwolf/historiens/Plutarque/index.htm.

SANTAMARÍA ÁLVAREZ, Marco Antonio. El edén griego: las islas de los bienaventurados, de Hesíodo a Platón. Respublica Litterarum, Suplemento Monográfico Utopía, 2006-1.

SANTOS YANGUAS, N. (1988). El mito de las islas afortunadas en la Antigüedad. In Memorias de Historia Antigua. Oviedo, 9, p. 166 - 175. SCHULTEN, A. (1945 1946). Las Islas de los Bienaventurados. In Ampurias. Barcelona, 7-8, p. 5- 22. 